\title{
Combined Effects of the MJO and the Arctic Oscillation on the Intraseasonal Eastern China Winter Temperature Variations
}

\author{
LEI SONG \\ Center for Monsoon System Research, Institute of Atmospheric Physics, Chinese Academy of Sciences, Beijing, China \\ RENGUANG WU \\ Center for Monsoon System Research, and State Key Laboratory of Numerical Modeling for Atmospheric Sciences \\ and Geophysical Fluid Dynamics, Institute of Atmospheric Physics, Chinese Academy of Sciences, Beijing, China
}

(Manuscript received 21 September 2018, in final form 24 January 2019)

\begin{abstract}
The present study reveals that the Madden-Julian oscillation (MJO)-related temperature anomalies over East Asia have notable differences among positive, neutral, and negative Arctic Oscillation (AO) phases. In MJO phases 2-3, cold anomalies over eastern China occur mainly during positive AO. In MJO phase 7, warm anomalies over eastern China are observed mostly during neutral AO, and in MJO phase 8 warm anomalies appear in positive and neutral AO. Regional mean temperature anomalies over northeastern East Asia tend to be negative during negative $\mathrm{AO}$ but positive during positive $\mathrm{AO}$ in six of eight MJO phases. In MJO phases $2-3$, the AO-related mid- to high-latitude wave train over Eurasia and the MJO convection-triggered poleward wave train work together in contributing to negative height anomalies over eastern China and leading to cold anomalies there. The mid- to high-latitude wave train is stronger when the AO is negative than positive, which is associated with stronger zonal winds. In MJO phases 7-8, the positive AO-related mid- to highlatitude wave train over Eurasia and the MJO-induced poleward wave train cooperate in inducing positive height anomalies and leading to warm anomalies over eastern China. The mid- to high-latitude wave train is the main contributor to negative height anomalies over eastern China when the AO is negative during MJO phases 7-8. Meanwhile, the intensity of the South Asian wave source associated with the MJO convection is subjected to the modulation of southeastward dispersion of wave energy from western Europe during negative AO.
\end{abstract}

\section{Introduction}

During boreal winter, large temperature drops during severe cold surges accompanied by snow or freezing rain can cause extensive damage (Kunkel et al. 1999; Wen et al. 2009; Zhou et al. 2009; Park et al. 2011). The occurrence of cold anomalies over East Asia has been linked to changes in the mid- to high-latitude circulation systems, including the intensification of the Siberian high (Ding and Krishnamurti 1987; Ding 1990; Zhang et al. 1997; Jeong and Ho 2005; Bueh et al. 2011; Shoji et al. 2014; Song and Wu 2017), the deepening of the East Asian trough (Zhang et al. 1997; Jeong and Ho 2005; Bueh et al. 2011; Song et al. 2016; Song and Wu 2017), and Rossby wave trains propagating along the polar front jet and the subtropical jet (Watanabe 2004;

Corresponding author: Renguang Wu, renguang@mail.iap.ac.cn
Takaya and Nakamura 2005a,b; Song et al. 2016; Song and $\mathrm{Wu}$ 2017).

The Arctic Oscillation (AO) (Thompson and Wallace 1998, 2000) is an important factor in the occurrence of cold events over East Asia (Gong et al. 2001; Wu and Wang 2002; Jeong and Ho 2005; Park et al. 2011; Park et al. 2014; Park and Ahn 2016; He et al. 2017; He et al. 2018; Song and $\mathrm{Wu}$ 2018). Previous studies have indicated that cold anomalies over East Asia can occur during both positive and negative AO phases (Jeong and Ho 2005; Park et al. 2010; Park et al. 2011; Park et al. 2014; Song and $\mathrm{Wu}$ 2018). Based on the monthly mean AO index, Jeong and Ho (2005) and Park et al. (2011) showed that the cold events over East Asia are more frequent during the negative $\mathrm{AO}$ phase than during the positive $\mathrm{AO}$ phase and the cold anomalies during the negative $\mathrm{AO}$ phase are much stronger and broader than those during the positive AO phase. Park et al. (2011, 
2014) categorized the cold events related to the AO into two types: the wave train type and the blocking type. They showed that the wave train type cold events happen during both positive and negative phases of the $\mathrm{AO}$, yet the blocking type cold events lean toward the negative AO phase. By employing the daily AO index, Song and $\mathrm{Wu}$ (2018) revealed that cold events over East Asia occur during both positive and negative phases of the AO, but the locations and extents of the cold anomalies are prominently different. The differences are associated with the location and intensity of the Rossby wave train, the Siberian high, and the East Asian trough. During negative AO, the enhanced Siberian high has a large spatial coverage over the mid- to high latitudes and the midtropospheric wave train along the polar front jet taking an eastward path. During positive AO, the high pressure anomalies over East Asia are located over the midlatitudes with a relatively small spatial coverage and the midtropospheric wave train along the polar front jet traveling by a southward path over Asia, inducing the development of a trough over subtropical East Asia.

Tropical intraseasonal variability such as the MaddenJulian oscillation (MJO) (Madden and Julian 1971, 1972) can also influence the emergence of cold anomalies over East Asia. The MJO is manifested as eastward propagation of convection and atmospheric circulation systems over the tropics with a time period of 30-90 days (Zhang 2005). The convection related to the MJO can excite tropospheric Rossby wave train through upperlevel divergence that acts as a Rossby wave source (Sardeshmukh and Hoskins 1988; Seo and Lee 2017) and equatorial Kelvin wave response (Jin and Hoskins 1995; Matthews et al. 2004). The poleward dispersion of the Rossby wave train triggered by the MJO can modulate the atmospheric circulation over mid- to high latitudes (Ferranti et al. 1990; Matthews et al. 2004; Kim et al. 2006; Seo and Son 2012) and influence the mid- and highlatitude winter climate (Yoo et al. 2012; Baxter et al. 2014; Seo et al. 2016). Jeong et al. (2005) analyzed the influence of the MJO on surface temperature variations over East Asia. According to their study, more cold surges occur when the MJO-related convection center is situated over the Indian Ocean. He et al. (2011) showed that MJO-related convection can modify the local Hadley circulation and the Rossby wave train and exert influence upon the wintertime climate over East Asia. Seo et al. (2016) indicated that local Hadley circulationinduced adiabatic subsidence is a main driver for temperature change over East Asia when the convection is situated over the Indian Ocean (i.e., MJO phase 3). Abdillah et al. (2018) showed that the westward or eastward location of the cold anomalies over East Asia is associated with the Rossby wave train excited by the MJO convection located over the Maritime Continent or the western Pacific.

As the winter circulation and climate over East Asia are impacted by both the $\mathrm{AO}$ and the MJO, this raises the possibility that the AO- or MJO-induced temperature anomalies over East Asia may depend upon their phase relationship. Previous studies have indicated that the MJO convection over the Indian Ocean tends to be connected to the positive AO phase and the negative AO is more closely associated with the negative MJO phases, that is, when the MJO convection is located over the western Pacific (Zhou and Miller 2005; L'Heureux and Higgins 2008). However, exceptions have been found (see L'Heureux and Higgins 2008, their Fig. 2). Therefore, it is meaningful to investigate how winter temperature anomalies over East Asia vary with the different combinations of MJO and AO phases. The questions to be addressed include the following: In which MJO phases do the MJO-related temperature anomalies over East Asia display large differences among the three AO phases? What are the individual and combined roles of AO- and MJO-induced atmospheric circulation anomalies? It should be noted that the relationship between the AO and the MJO is very complicated, including dynamical processes from the troposphere (e.g., Zhou and Miller 2005) to the stratosphere (e.g., Garfinkel et al. 2012; Garfinkel and Schwartz 2017) on different time scales. This study focuses on the combined effects of the MJO and AO over eastern China on intraseasonal time scales and will not investigate the interaction between the $\mathrm{AO}$ and the MJO. Song and $\mathrm{Wu}$ (2018) indicated that cold anomalies over eastern China can be associated with both positive and negative $\mathrm{AO}$ on an intraseasonal time scale. Different from Song and $\mathrm{Wu}$ (2018), the present study considers the combined effect of the $\mathrm{AO}$ and the MJO upon the temperature anomalies over eastern China on intraseasonal time scales.

The remaining parts of this study are organized as follows. The dataset and the methodology are described in section 2. Section 3 presents basic features of the MJO influence upon the East Asian wintertime temperature anomalies. Section 4 depicts the combined effect of the $\mathrm{MJO}$ and the $\mathrm{AO}$ on temperature anomalies over East Asia. Section 5 investigates the atmospheric circulation anomalies of the combined effect of the MJO and the AO. A summary and some discussion are given in section 6 .

\section{Data and methodology}

The daily data in the present study are obtained from the National Centers for Environmental Prediction 
(NCEP)-Department of Energy (DOE) Reanalysis 2 provided by the NOAA/OAR/ESRL Physical Science Division (PSD) (Kanamitsu et al. 2002). This study focuses on 37 winters (December, January, and February) from 1979 to 2016. The daily variables include geopotential height, sea level pressure, outgoing longwave radiation (OLR), meridional and zonal winds, air temperature, surface air temperature, and wind. The anomalies are obtained by removing the climatological daily mean for the period 1980-2010. The pressure level data have a horizontal resolution of $2.5^{\circ} \times 2.5^{\circ}$ at 17 layers from 1000 to $10 \mathrm{hPa}$. Surface data are on the T62 Gaussian grid.

The phases of the MJO are depicted by the daily Realtime Multivariate MJO (RMM) index (Wheeler and Hendon 2004). The daily RMM index is obtained from the Bureau of Meteorology of Australia (http://www. bom.gov.au/climate/mjo/graphics/rmm.74toRealtime.txt). The daily AO index is obtained from the NOAA Climate Prediction Center (CPC) website (http://www.cpc.ncep. noaa.gov/products/precip/CWlink/daily_ao_index/ao. shtml).

Composite analysis is conducted based on the eight MJO phases categorized by the RMM index, as well as the AO phases. The composite anomalies for each MJO phase are the average of anomalies over the 5-day period after that MJO phase (Li et al. 2018). The Student's $t$ test is employed to estimate the significance of the composite anomalies. The propagation of the tropospheric Rossby wave train is depicted by the Rossby wave activity fluxes (Plumb 1985; Takaya and Nakamura 2001).

\section{The surface temperature anomalies over East Asia in different MJO phases}

The winter surface temperature anomalies over East Asia during the eight phases of the MJO have been analyzed by Jeong et al. (2005) and Seo et al. (2016). By using daily mean surface air temperature data at 192 Chinese stations and 5 Korean stations in the winters from 1974/75 to 2000/01, Jeong et al. (2005) obtained composite surface temperature anomalies with respect to the eight phases of the MJO. As shown in their Fig. 1, cold anomalies over East Asia appear in phases 3 and 4, whereas warm anomalies are observed in phases 6 and 7 . Similar features were obtained by Seo et al. (2016) based on Global Historical Climatology Network station data for the period 1979-2010.

Cold anomalies appear over western Siberia and the region north of $30^{\circ} \mathrm{N}$ over East Asia in MJO phase 1 (Fig. 1a). The region of cold anomalies extends southward and covers most of East Asia in phase 2 with the center of the cold anomalies located south of Lake Baikal (Fig. 1b). In phase 3, the main body of cold anomalies is situated over eastern China and northeastern East Asia (Fig. 1c). This feature is similar to that obtained by Jeong et al. (2005) (see their Fig. 1, phase 3) and by Seo et al. (2016) (see their Fig. 1c). In phase 4, the cold anomalies over East Asia are weakened (Fig. 1d). In phase 5, there is a weak recovery of cold anomalies over northeastern East Asia (Fig. 1e), consistent with Jeong et al. (2005). After phase 5, warm anomalies develop over East Asia (Figs. 1f-h). But the intensity of warm anomalies appears to be weaker than in Jeong et al. (2005) and Seo et al. (2016).

The temporal changes in surface air temperature anomalies with MJO phases are related to the evolution of MJO-related tropical convection and associated atmospheric circulation. In phase 1 , a large suppressed convection region is located over the equatorial western Pacific, accompanied by an anomalous upper-level cyclone over southeastern Asia (Fig. 2a). Meanwhile, an anomalous convective center appears over the equatorial western Indian Ocean in phase 1. It intensifies and moves eastward thereafter (Figs. 2a-c). As a response to this anomalous heating, an anomalous anticyclone develops at the upper level off the equator to the northwest of the heating. Rossby wave activity fluxes originating from the anomalous anticyclone propagate northeastward to East Asia. This leads to the development of cyclonic anomalies over East Asia, which contributes to the deepening of the East Asian trough and the formation of cold anomalies over East Asia (Figs. 1b,c). With the eastward movement of the anomalous convective center, the anomalous heating expands in its meridional extent, getting closer to the subtropical waveguide (Matthews et al. 2004) in phase 3 (Fig. 2c). As a result, the poleward propagation of Rossby wave train becomes more evident. The cyclonic anomalies over East Asia shift southeastward, which contributes to the southeastward movement of the cold anomalies (Fig. 1c).

When the convective anomalies reach the Maritime Continent in phase 4 (Fig. 2d), the Rossby wave energy dispersion is weakened since the anomalous convection is away from the subtropical jet (Matthews et al. 2004). This leads to the weakening of the cyclonic anomalies over East Asia (Fig. 2d) and the diminishing of surface cold anomalies (Fig. 1d). After phase 4, the offequatorial response to the $\mathrm{MJO}$ convective heating is reversed (Figs. 2e-h) (Seo and Son 2012). The poleward dispersion of Rossby wave energy and corresponding height anomalies are weaker over East Asia (Figs. 2e-h). Accordingly, the midlatitude surface temperature anomalies (Figs. 1e-h) appear to be smaller in 

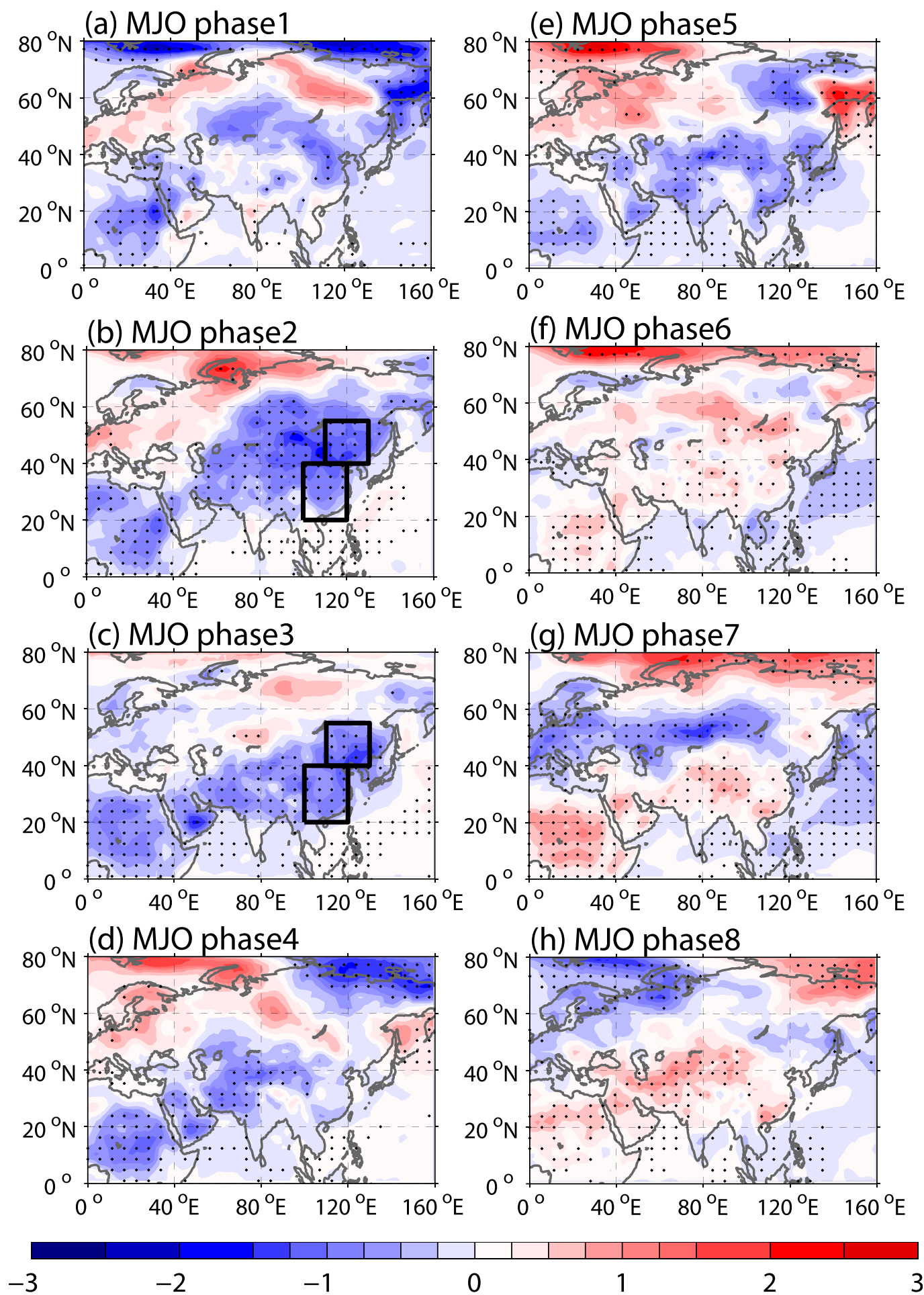

FIG. 1. Composite surface air temperature anomalies (shading; ${ }^{\circ} \mathrm{C}$ ) in phases $1-8$ of the MJO. Black dots denote temperature anomalies significant at the $95 \%$ confidence level. Black boxes in (b) and (c) denote the regions where area-mean temperature anomalies are calculated in Fig. 3. 

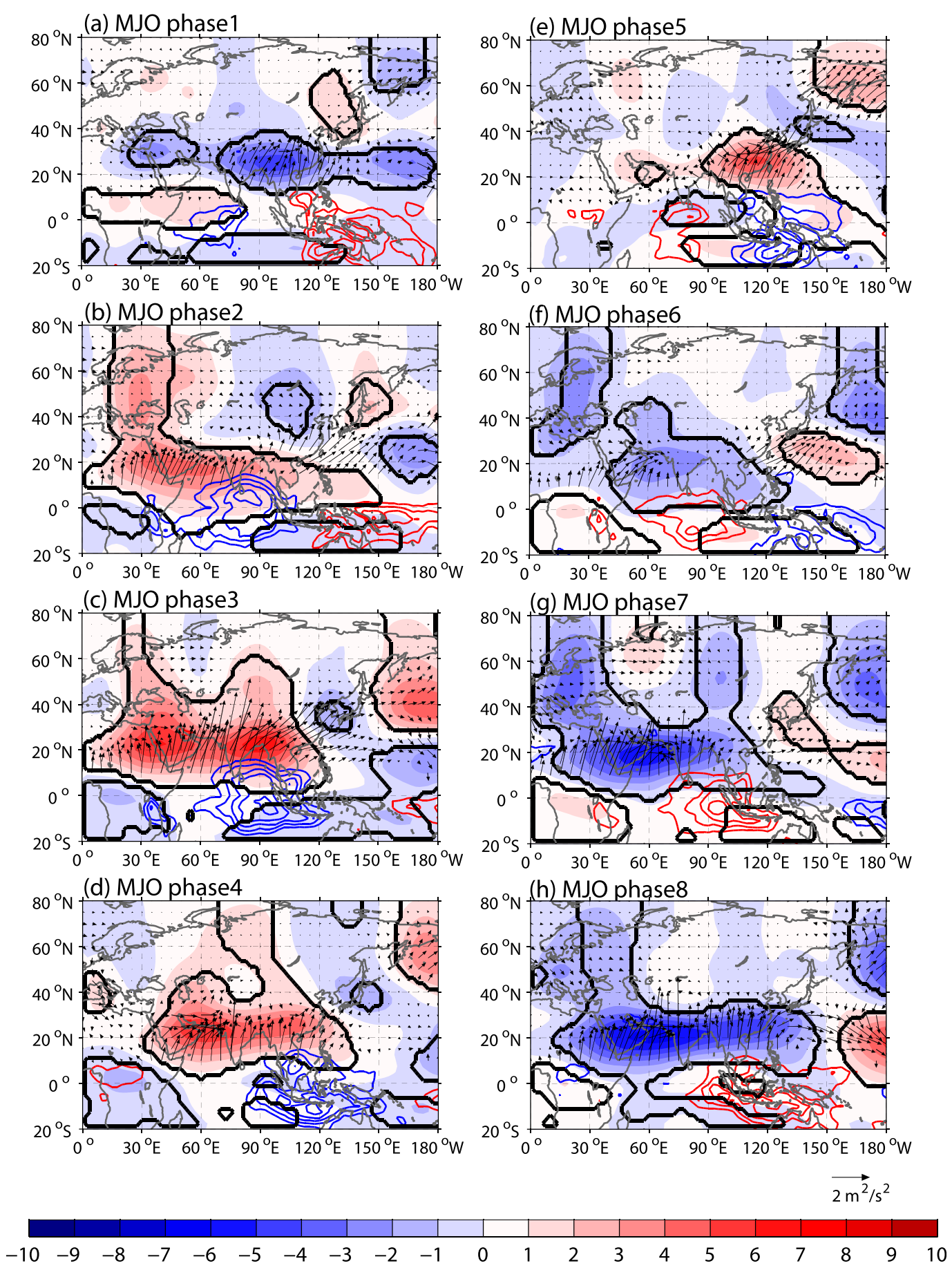

FIG. 2. Composite OLR anomalies (contour; interval: $4 \mathrm{~W} \mathrm{~m}^{-2}$, blue and red contours indicate the negative and positive anomalies, respectively), streamfunction anomalies (shading; $\times 10^{6} \mathrm{~m}^{2} \mathrm{~s}^{-2}$ ), and wave activity flux $\left(\mathrm{m}^{2} \mathrm{~s}^{-2}\right.$ ) (vector, scale at the bottom right) at $300 \mathrm{hPa}$ in phases 1-8 of the MJO. Black contours denote streamfunction anomalies significant at the $95 \%$ confidence level.

magnitude compared to those in phases $2-3$. In phase 5, evident temperature anomalies are observed off the coast of eastern China (Fig. 1e), which corresponds to the enhancement of the cyclonic anomalies over northeastern Asia (Fig. 2e). The cold anomalies gradually move eastward to Japan and the northwestern Pacific afterward, accompanied by northeastward move of the cyclonic anomalies (Figs. 1f,g and 2f,g). 


\section{The combined effects of the MJO and the AO on surface temperature anomalies over East Asia}

To investigate how the MJO-related temperature anomalies over East Asia vary with the phases of AO, we construct composite for the eight MJO phases separately for positive, neutral, and negative AO index in this section. For this purpose, each MJO phase is divided into three subgroups depending on the AO phases: positive $\mathrm{AO}$ phase (the $\mathrm{AO}$ index exceeds $+\sigma$ ), negative AO phase (the AO index is smaller than $-\sigma$ ) and neutral AO phase (when absolute value of the AO index is smaller than $\sigma$ ). Here, $\sigma$ denotes the standard deviation of daily AO index.

The numbers of days in each subgroup are presented in Fig. 3a. The number of days in each of the eight MJO phases exceeds 250 . The large sample size makes the composites (Fig. 1) based on the MJO phases reliable. The neutral AO phase has the largest number of days in 5 of $8 \mathrm{MJO}$ phases. There are more positive AO days than negative AO days in phases 2 to 5 , which is consistent with Zhou and Miller (2005) and L'Heureux and Higgins (2008), who showed that the MJO convection over the Indian Ocean prefers to be connected to the positive AO phase. There are more negative AO days than positive AO days in phases 6-8.

To illustrate the combined impacts of the MJO and AO upon temperature anomalies over East Asia, we present in Figs. $3 \mathrm{~b}$ and $3 \mathrm{c}$ regional mean temperature anomalies over eastern China $\left(20^{\circ}-40^{\circ} \mathrm{N}, 100^{\circ}-120^{\circ} \mathrm{E}\right)$ and northeastern East Asia $\left(40^{\circ}-55^{\circ} \mathrm{N}, 110^{\circ}-130^{\circ} \mathrm{E}\right)$ in each MJO phase for different AO phases. The domains of the two regions are marked by black boxes in Figs. $1 \mathrm{~b}$ and 1c. The two regions are selected because surface temperature anomalies in these regions are often concerns of previous studies due to their significant impacts in boreal winter (Wen et al. 2009; Park et al. 2011; Song and $\mathrm{Wu} 2017,2018)$.

The partition of MJO-related surface temperature anomalies over East Asia among the three AO phases varies obviously with the MJO phase. The MJO-related temperature anomalies over eastern China are negative in phases 2-3 and switch to positive in phases 7 and 8 (Fig. 3b). The regional mean negative temperature anomalies in phase 2 occur in positive $\mathrm{AO}$, and those in negative $\mathrm{AO}$ are not significant. The negative temperature anomalies in phase 3 are mainly associated with positive $\mathrm{AO}$, which is in agreement with previous studies (Park et al. 2011; Song and $\mathrm{Wu} 2018$ ). In phase 5, negative temperature anomalies are largely linked to negative AO. The positive temperature anomalies in phases 6 and 7 are mainly related to neutral AO. In phase 8, positive temperature anomalies are more likely to occur in the positive AO phase.
The regional mean surface temperature anomalies over northeastern East Asia in six of the eight MJO phases tend to be large in positive and negative AO phases. They are small in neutral AO phase except for MJO phases 5, 7, and 8 (Fig. 3c). The regional mean temperature anomalies are positive when the $\mathrm{AO}$ is positive and negative when the $\mathrm{AO}$ is negative in six of the eight MJO phases. This feature indicates a dependence of surface temperature anomalies over northeastern East Asia on the signs of the AO.

The above analysis indicates that the MJO-related surface temperature anomalies differ largely among the three AO phases. In some MJO phases, the MJOrelated temperature anomalies are mainly associated with positive $\mathrm{AO}$, whereas in other $\mathrm{MJO}$ phases the MJO-related temperature anomalies are mostly linked to negative AO. The dependency of the MJO influence on the AO phase also differs in the two regions. The MJO-related temperature anomalies over eastern China are evident in phases $2-3$ and phases 7-8 when the MJO convective center resides over the Eastern Hemisphere and Western Hemisphere, respectively (L'Heureux and Higgins 2008). Thus, we will focus on the MJO phases 2-3 and 7-8 to investigate how the different combinations of the AO and MJO phases induce atmospheric circulation and temperature anomalies over eastern China. Before that, we compare the difference of MJOrelated temperature anomalies in these MJO phases among positive, neutral, and negative $\mathrm{AO}$ phases.

For MJO phases 2 and 3, when the AO is positive, the temperature anomalies are characterized by a zonally extended dipole pattern (Figs. 4a and 4d). The region south of $40^{\circ} \mathrm{N}$ is covered by negative anomalies, whereas positive anomalies cover most of the regions north of $40^{\circ} \mathrm{N}$. The temperature anomaly patterns in both MJO phases 2 and 3 for positive AO are similar to those constructed for positive $\mathrm{AO}$ when the MJO phase is not considered (Park et al. 2011; Song and Wu 2018). The cold anomalies in negative AO also correspond to those for negative AO obtained in a previous study (Park et al. 2011), extending eastward from western Europe to Siberia and then southeastward to northeastern East Asia (Figs. 4c and 4f). The temperature anomalies over eastern China are relatively weak. When the AO is neutral, temperature anomalies are weak over East Asia except for the positive temperature anomalies over northern Lake Baikal in MJO phase 3 (Figs. 4b and 4e). The above results indicate a weak influence of the MJO upon temperature anomalies over eastern China in its phases 2 and 3 without the support of the AO.

Distinct surface temperature anomalies in MJO phases 7 and 8 are obtained corresponding to different $\mathrm{AO}$ phases as well. Zonally extended positive and negative 
(a) Number of days

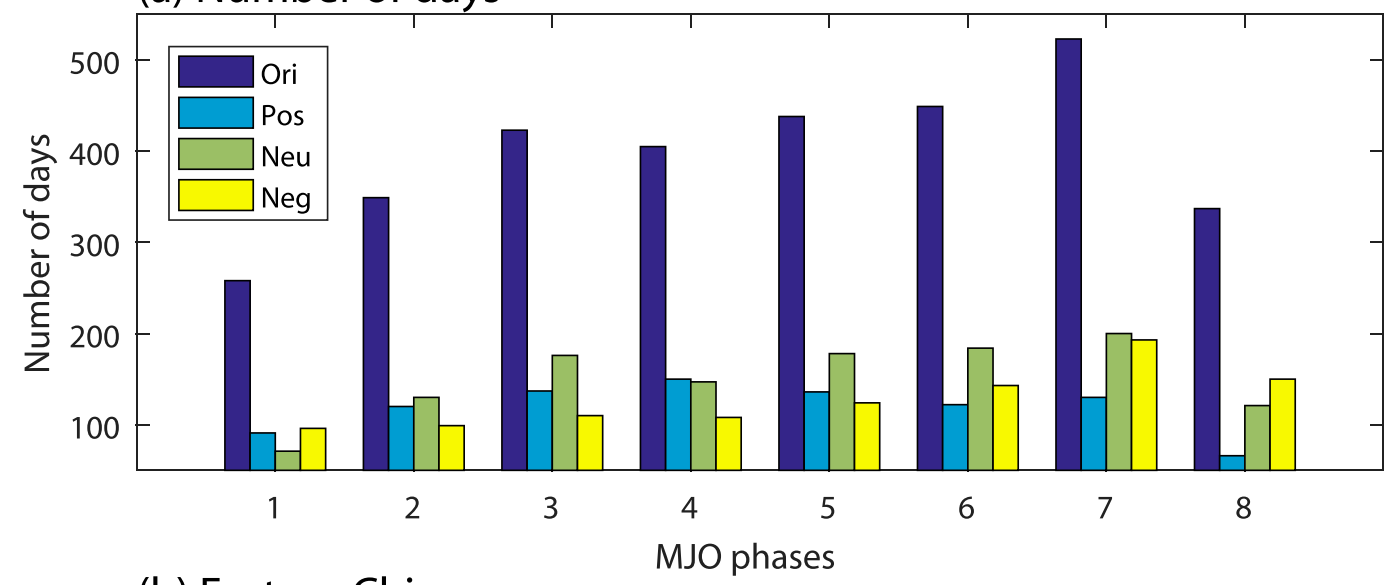

(b) Eastern China
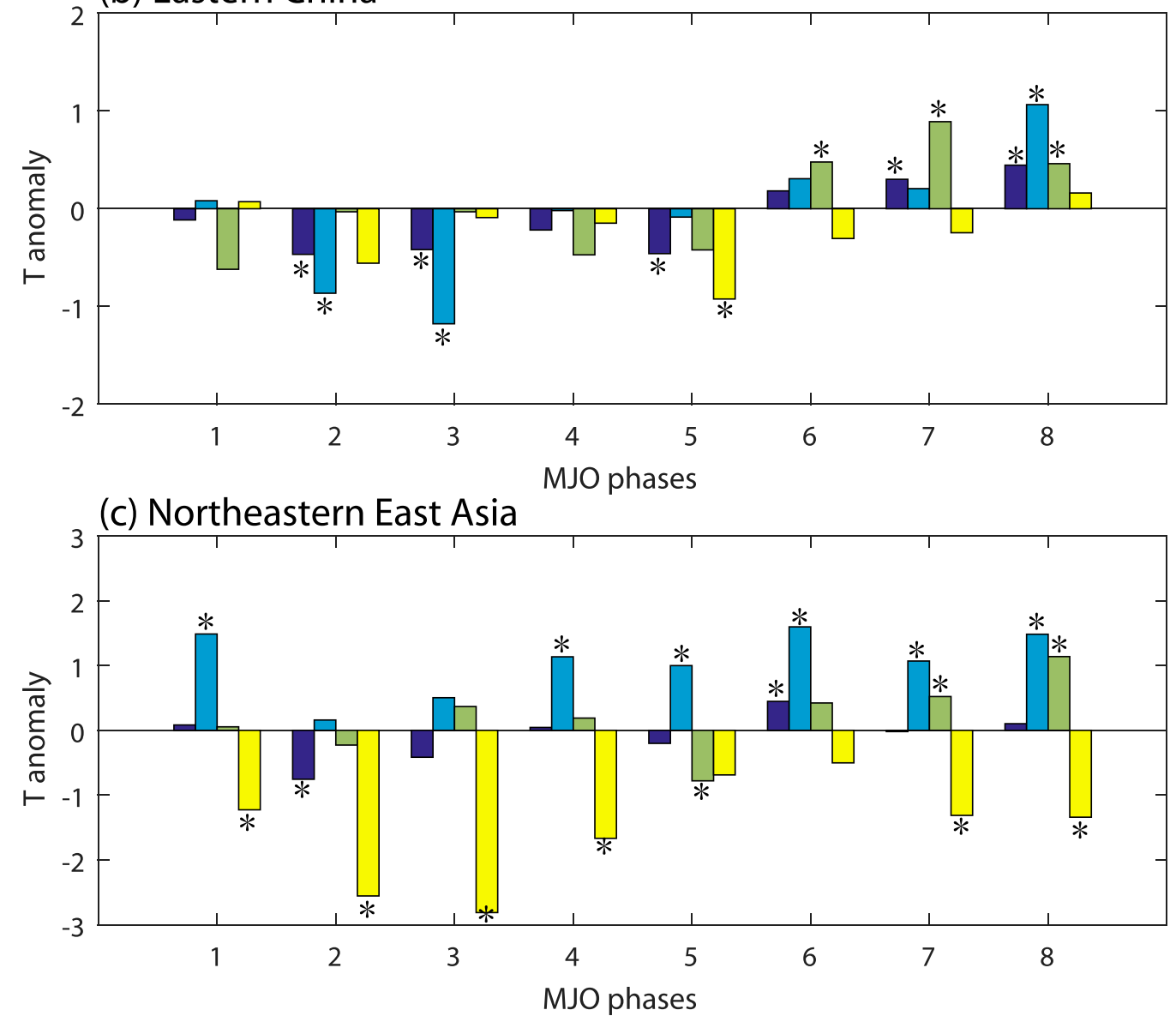

FIG. 3. (a) The number of days for the eight MJO phases (dark blue bars) and those when AO is positive (light blue bars), neutral (light green bars), and negative (yellow bars) during all the winters for the period 1979-2016. Also shown are the regional mean surface temperature anomalies over the regions of (b) $20^{\circ}-40^{\circ} \mathrm{N}, 100^{\circ}-120^{\circ} \mathrm{E}$ and (c) $40^{\circ}-55^{\circ} \mathrm{N}, 110^{\circ}-130^{\circ} \mathrm{E}$ for the eight $\mathrm{MJO}$ phases (dark blue bars) and those when AO is positive (light blue bars), neutral (light green bars), and negative (yellow bars) during all the winters for the period 1979-2016. Black asterisks denote regional mean surface temperature anomalies significant at the $95 \%$ confidence level. 

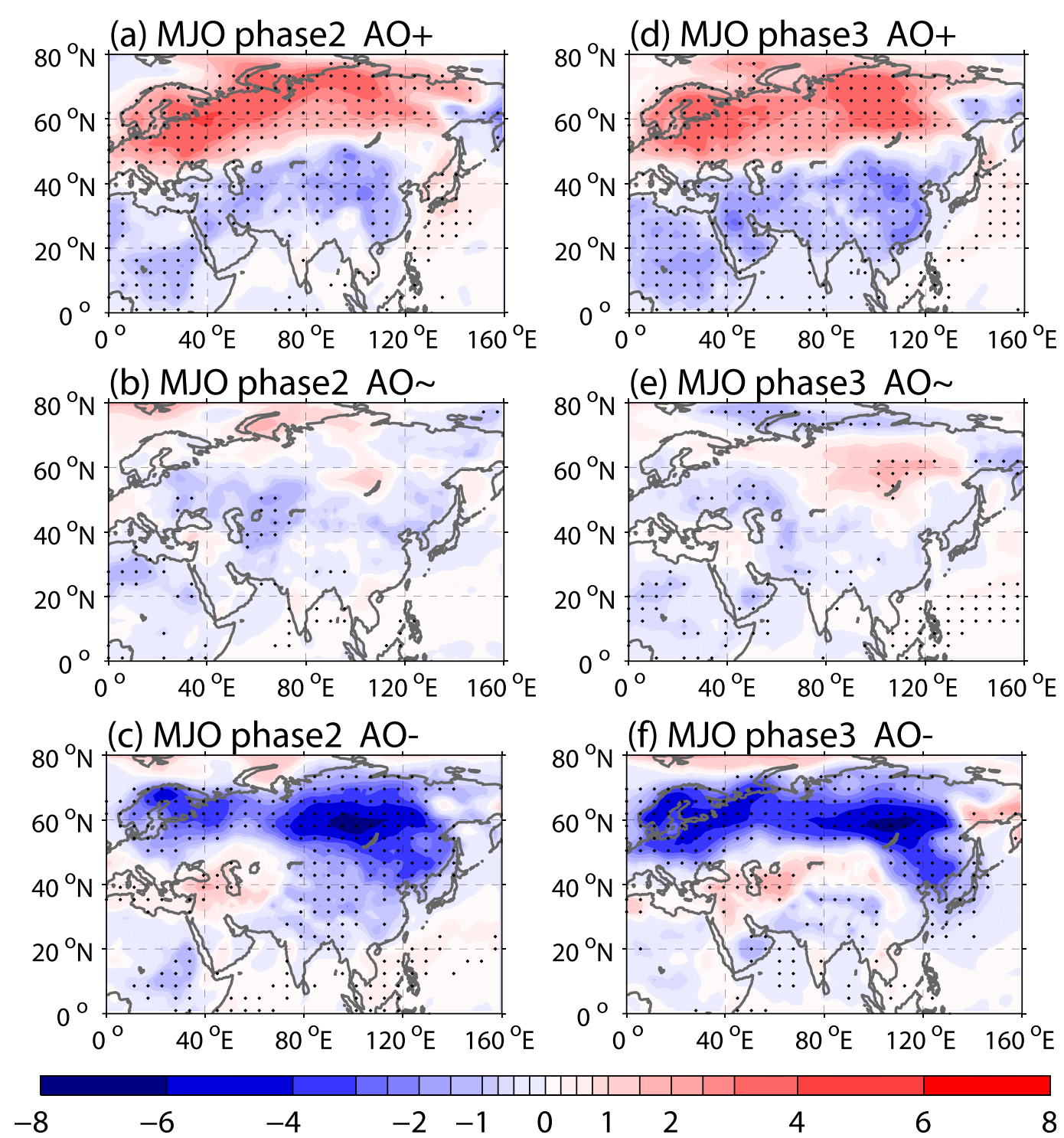

$\begin{array}{llllllllllr}-8 & -6 & -4 & -2 & -1 & 0 & 1 & 2 & 4 & 6 & 8\end{array}$ FIG. 4. Composite surface air temperature anomalies (shading, ${ }^{\circ} \mathrm{C}$ ) during MJO phases 2 and 3 of the (a),(d) positive
AO, (b),(e) neutral AO, and (c),(f) negative AO.

temperature anomalies are observed over the high latitudes in the positive and negative AO phases, respectively (Figs. 5a,c,d,f). The positive temperature anomalies in MJO phase 8 extend southward in positive AO (Fig. 5d). The region south of $40^{\circ} \mathrm{N}$ is covered by positive temperature anomalies in MJO phase 7 during neutral AO (Fig. 5b). In MJO phase 8 with neutral AO, positive anomalies are observed over the regions from Siberia to northeastern Asia (Fig. 5e). The temperature anomalies over eastern China in MJO phases 7-8 are weak when the MJO is accompanied by negative AO (Figs. 5c,f).

The surface temperature and wind anomalies in positive, neutral, and negative AO phases are further compared in the Hovmöller diagrams along $100^{\circ}-120^{\circ} \mathrm{E}$
(Fig. 6). During positive AO, the cold anomalies south of $50^{\circ} \mathrm{N}$ during $\mathrm{MJO}$ phases 2 to 3 are accompanied by northerly wind anomalies, and warm anomalies in phase 8 extending southward to the midlatitude are accompanied by southerly wind (Fig. 6a). During neutral AO, positive temperature anomalies in MJO phases 6 to 8 are observed between $25^{\circ}$ and $50^{\circ} \mathrm{N}$ (Fig. 6b). During negative $\mathrm{AO}$, the southward extension of cold anomalies is evident in MJO phases 1, 2, and 5 (Fig. 6c). The temperature anomalies are opposite in the high latitudes during positive and negative AO phases (Figs. 6a,c). From the above comparison, the high-latitude Asian temperature anomalies are mainly controlled by the AO, whereas the midlatitude East Asian temperature 

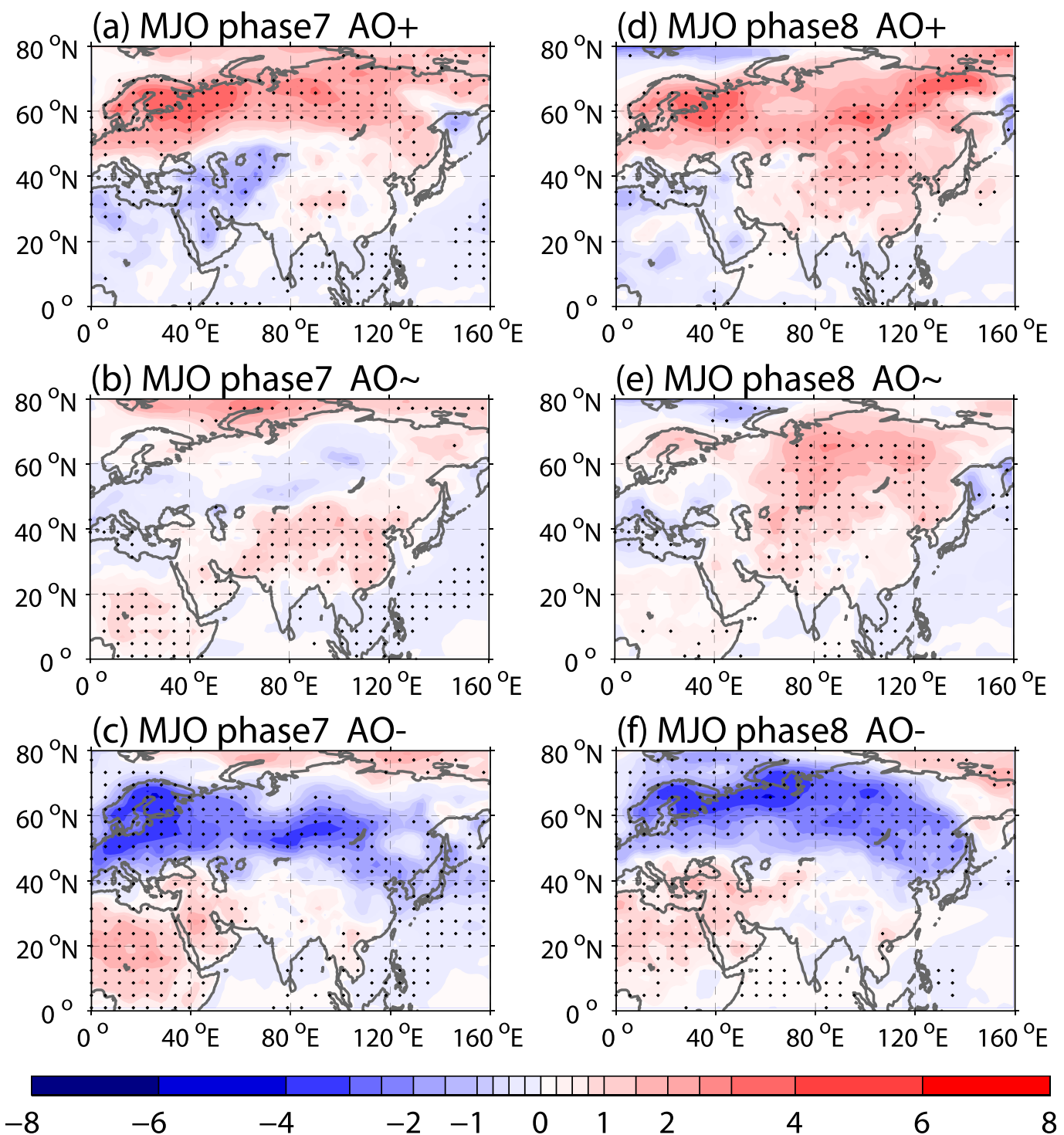

$\begin{array}{llllllllllll}-8 & -6 & -4 & -2 & -1 & 0 & 1 & 2 & 4 & 6 & 8\end{array}$

FIG. 5. Composite surface air temperature anomalies (shading, ${ }^{\circ} \mathrm{C}$ ) during MJO phases 7 and 8 of the (a),(d) positive AO, (b),(e) neutral AO, and (c),(f) negative AO.

anomalies may be contributed by both the MJO and the AO.

\section{The combined effects of the MJO and the AO on atmospheric circulation anomalies}

Analysis in the previous section presents clear evidence for the combined effects of the $\mathrm{MJO}$ and the $\mathrm{AO}$ on surface temperature anomalies over East Asia. The temperature anomalies are associated with atmospheric circulation changes. In this section, we compare atmospheric circulation patterns in different combinations of the MJO and the AO phases. Before that, we compare the atmospheric circulation anomalies in positive and negative AO phases.
During positive $\mathrm{AO}$, an anomalous anticyclonecyclone-anticyclone pattern is located over the midto high-latitude Eurasian continent (Fig. 7a). Wave activity fluxes emit from the anticyclonic wave source over western Europe and split into two parts. One goes eastward over the mid- to high latitudes and turns northeastward over the Russian Far East. The other goes southeastward to the Arabian Peninsula and the Arabian Sea. The accompanying incoming Rossby wave energy induces an anticyclone anomaly over the northern Arabian Sea. The anomalous streamfunction pattern in the negative AO phase (Fig. 7b) is similar to that in the positive AO phase except for the reversed sign. The wave activity fluxes over the middle to high 
(a) $\mathrm{AO}+$

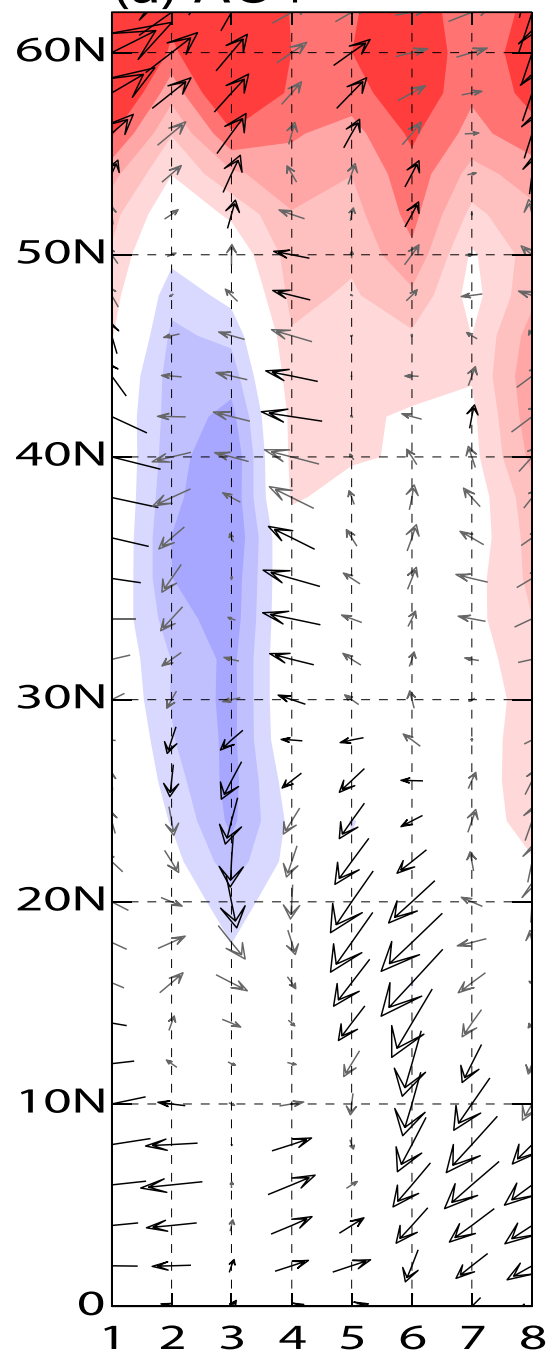

(b) $\mathrm{AO} \sim$

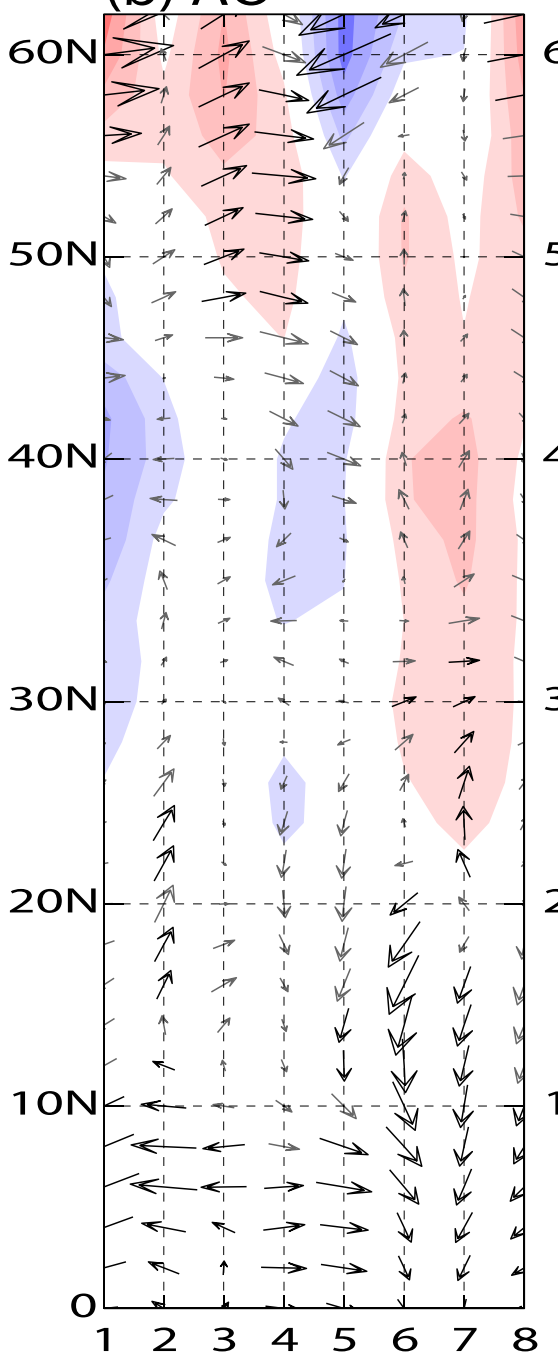

(c) $\mathrm{AO}-$

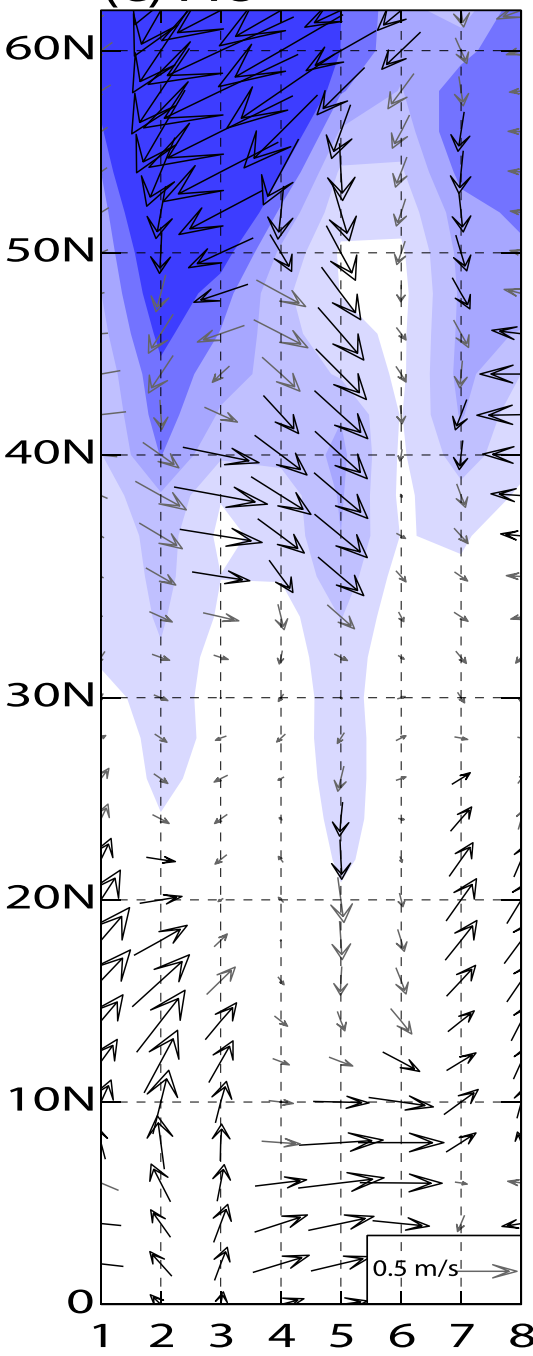

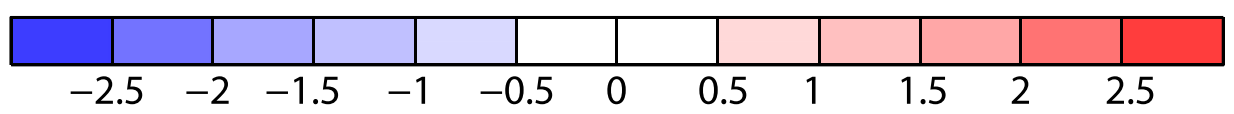

FIG. 6. Hovmöller diagram of surface air temperature anomalies (shading; ${ }^{\circ} \mathrm{C}$ ) and wind anomalies (vector; $\mathrm{m} \mathrm{s}{ }^{-1}$, scale at the rightbottom corner) along $100^{\circ}-120^{\circ} \mathrm{E}$ with respect to the eight $\mathrm{MJO}$ phases during (a) positive $\mathrm{AO}$, (b) neutral AO, and (c) negative AO. Black vectors denote wind anomalies significant at the $95 \%$ confidence level.

latitudes are larger in negative $\mathrm{AO}$ phase than in positive AO phase.

The above streamfunction anomaly pattern and wave activity fluxes suggest two ways for the AO to modulate the East Asian atmospheric circulation. One is through the Rossby wave train over the mid- to high-latitude Eurasian continent. The other is through the southeastward dispersion of Rossby wave energy that induces an anomalous anticyclone or cyclone over the Arabian Sea. As shown in Fig. 2, the Arabian Sea is a region subject to the influence of MJO-related tropical convective heating, from which the MJO-triggered tropical wave train emits and propagates to East Asia. As such, the AO may affect the atmospheric circulation over East Asia through regulating the source of the MJOtriggered tropical wave train. Here, we compare the atmospheric circulation anomalies in MJO phases 2-3 and phases 7-8 in combination with different AO phases.

The differences of circulation patterns in MJO phases 2 and 3 when the AO is positive and negative include the effects of MJO. In MJO phase 2, the mid- to highlatitude wave train is stronger in negative AO than in positive AO (Figs. 8a,c). The anomalous upper-level anticyclone over South Asia is much stronger in positive 

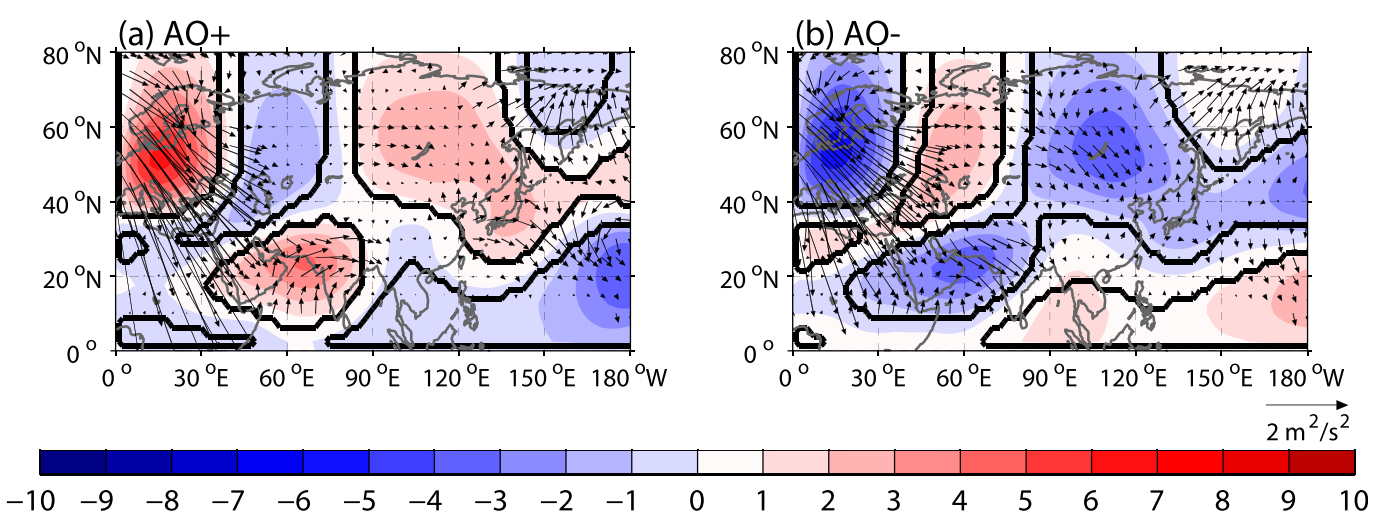

FIG. 7. Composite streamfunction anomalies (shading; $\times 10^{6} \mathrm{~m}^{2} \mathrm{~s}^{-2}$ ) and wave activity flux (vector; $\mathrm{m}^{2} \mathrm{~s}^{-2}$; scale at bottom right) at $300 \mathrm{hPa}$ during (a) positive and (b) negative AO. Black contours denote streamfunction anomalies significant at the $95 \%$ confidence level.

AO than in negative AO. This difference may be explained by the constructive interference between the MJO and the AO (Zhou and Miller 2005). As noted above, anomalous heating over the tropical Indian Ocean triggers an anomalous anticyclone over South Asia as a Rossby wave response (Fig. 2). A branch of southeastward dispersion of wave energy emerges from western Europe, which has opposite streamfunction anomalies during positive and negative $\mathrm{AO}$ phases (Fig. 7).

When the $\mathrm{AO}$ is positive, the height anomalies over South Asia are in phase with those due to the MJO and thus enhance the anomalous anticyclone. As indicated by the Rossby wave activity fluxes, the northeastward propagating Rossby wave train originating from the anticyclonic anomalies over the Arabian Sea induces anomalous cyclone over subtropical East Asia (Fig. 8a), which is conducive to the formation of cold anomalies over eastern China (Fig. 4a) (Song and Wu 2017). When the AO is negative, the height anomalies over South Asia are opposite to those due to the MJO, leading to a weaker anomalous anticyclone over southeastern Asia (Fig. 8c). Accordingly, the northeastward wave activity fluxes shift eastward over East Asia. As such, the mid- to high-latitude wave train has a dominant role in inducing negative height anomalies over East Asia so that the anomalous cyclone over East Asia is located at higher latitude (Fig. 8c), leading to northward located cold anomalies (Fig. 4c). A generally similar difference is observed in MJO phase 3 (Figs. 8d,f). Compared to MJO phase 2, the wave train over mid- to high-latitude Eurasia is evident in MJO phase 3 when the AO is positive, but the anomalous cyclone over East Asia is weaker, which may be due to the development of anomalous anticyclone over the Lake Baikal (Fig. 8d). The streamfunction anomaly pattern during neutral $\mathrm{AO}$ is similar to that when the $\mathrm{AO}$ is not taken into account (Figs. $2 \mathrm{~b}$ and $2 \mathrm{c}$ ).

The effects of the MJO on the differences of circulation patterns between positive and negative $\mathrm{AO}$ are observed in MJO phases 7 and 8. Rossby wave trains appear over mid- to high-latitude Eurasia in both positive and negative AO phases with opposite signs of streamfunction anomalies (Figs. 9a,c,d,f). In the positive AO phase, the wave train corresponds to positive height anomalies over the midlatitude East Asia (Figs. 9a,d). In the negative AO, negative height anomalies occupy mid- to high-latitude East Asia (Figs. 9c,f). Meanwhile, the AO-related anomalies are in phase with the MJOrelated anomalies over South Asia, enhancing the anomalous cyclone there (Figs. 9c,f). In the neutral AO phase, the mid- to high-latitude wave train-related height anomalies are weak (Figs. 9b,e). The anomalous cyclone over South Asia is stronger in negative AO than in positive $\mathrm{AO}$, which is attributed to the role of $\mathrm{AO}$ related southeastward dispersion of wave energy from western Europe. In positive AO phase, the AO-related anomalies are opposite to the MJO-related anomalies, weakening the anomalous cyclone over South Asia (Figs. 9a,d). Over East Asia and the western North Pacific, obvious northward wave activity fluxes are observed in positive AO (Figs. 9a,d), which contributes to anomalous anticyclone over the midlatitudes, leading to positive temperature anomalies over East Asia (Fig. 5d). The wave activity fluxes go eastward over the subtropics in negative $\mathrm{AO}$ and thus negative height anomalies dominate high-latitude Asia (Figs. 9c,f). As such, negative temperature anomalies are confined to northeastern East Asia (Figs. 5c,f). The weakening of the poleward dispersion of the wave energy in negative AO phase is associated with the weakened meridional pressure gradient between high-latitude and subtropical Asia 

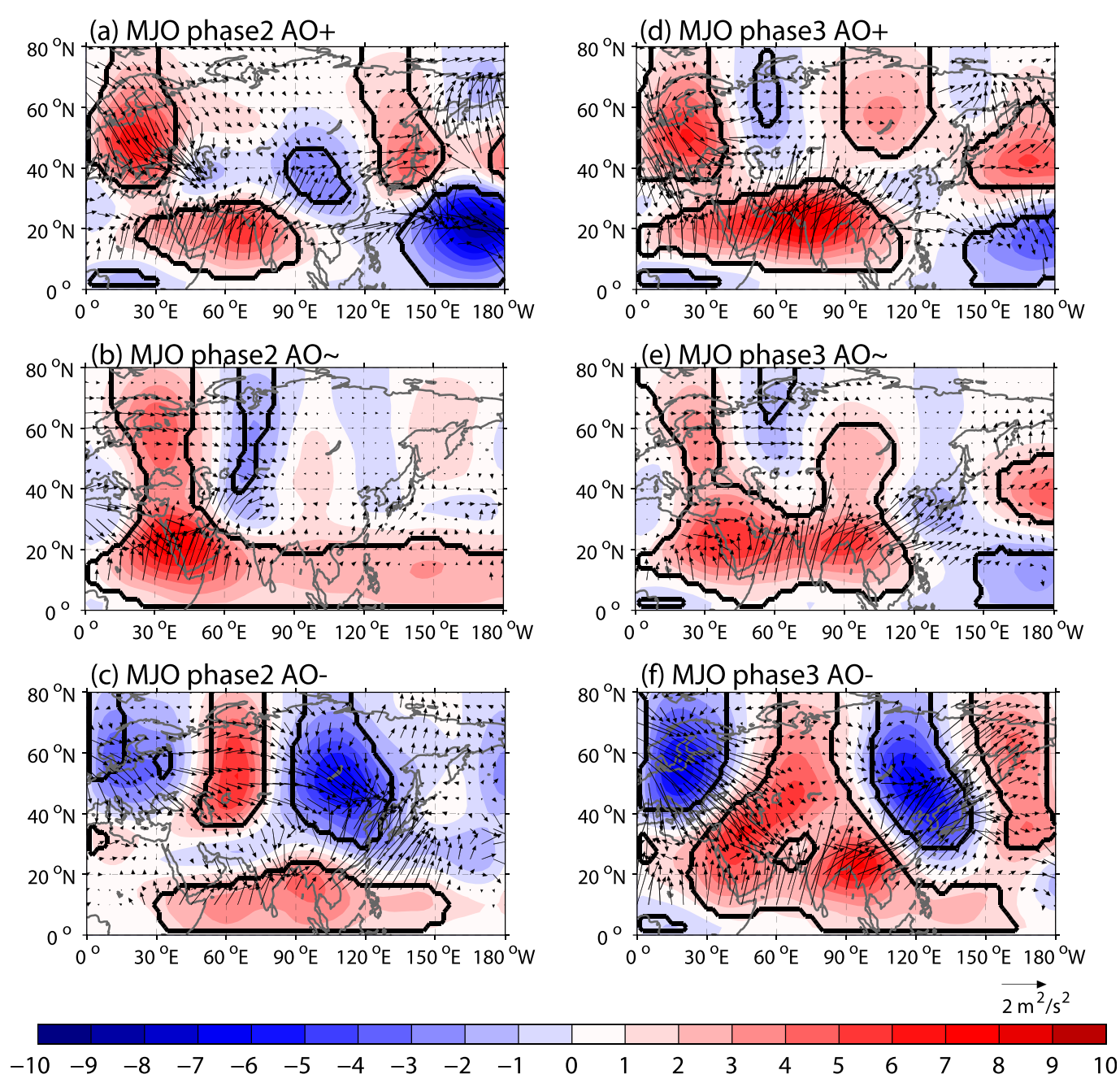

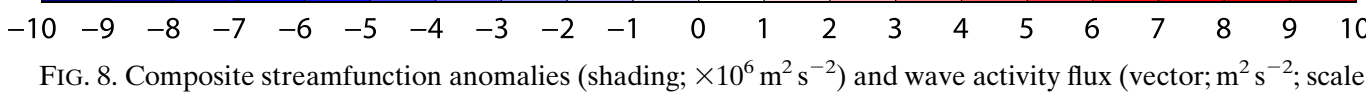
at bottom right) at $300 \mathrm{hPa}$ for MJO phases 2 and 3 during (a),(d) positive, (b),(e) neutral, and (c),(f) negative AO. Black contours denote streamfunction anomalies significant at the $95 \%$ confidence level.

(Takaya and Nakamura 2001). The northeastward wave activity fluxes are observed along the East Asian coast in neutral AO, particularly in MJO phase 7, which contributes to anomalous anticyclone over the Korean peninsula (Fig. 9b). This anomalous anticyclone leads to the development of positive temperature anomalies over eastern China (Fig. 5b).

From the above analysis, the location and intensity of cold anomalies over East Asia in MJO phases 2 and 3 are determined by a combined effect of the mid- to highlatitude wave train and the MJO-forced poleward wave train. The difference in the MJO-induced poleward wave train between positive and negative $\mathrm{AO}$ in $\mathrm{MJO}$ phases 2 and 3 is related to the location of the wave source forced by the MJO convection. The anticyclonic wave source is enhanced by the southeastward wave energy dispersion during positive $\mathrm{AO}$ (Figs. $7 \mathrm{a}$ and $8 \mathrm{a}, \mathrm{d}$ ), whereas it is weakened and pushed eastward by the cyclonic anomalies over the Arabian Sea in negative AO (Figs. $7 \mathrm{~b}$ and $8 \mathrm{c}, \mathrm{f}$ ). This leads to an eastward shift in the location of the poleward wave train during negative AO. The location and sign of temperature anomalies over East Asia in MJO phases 7 and 8 are also related to whether the mid- to highlatitude wave train and the MJO forced poleward wave train work in cooperation or not. In positive $\mathrm{AO}$ phase, the MJO convection induced cyclonic wave source shifts eastward and the two wave trains both contribute to the positive height anomalies over East Asia (Figs. 7a and 9a,d). In negative AO phase, the MJO-related cyclonic wave source is located westward with a larger intensity due to the effect of AO. The MJO-related wave train mainly goes eastward along the subtropics, and the height anomalies over East Asia are mainly attributed to the AO-related mid- to high-latitude wave train (Figs. $7 \mathrm{~b}$ and 9c,f). 

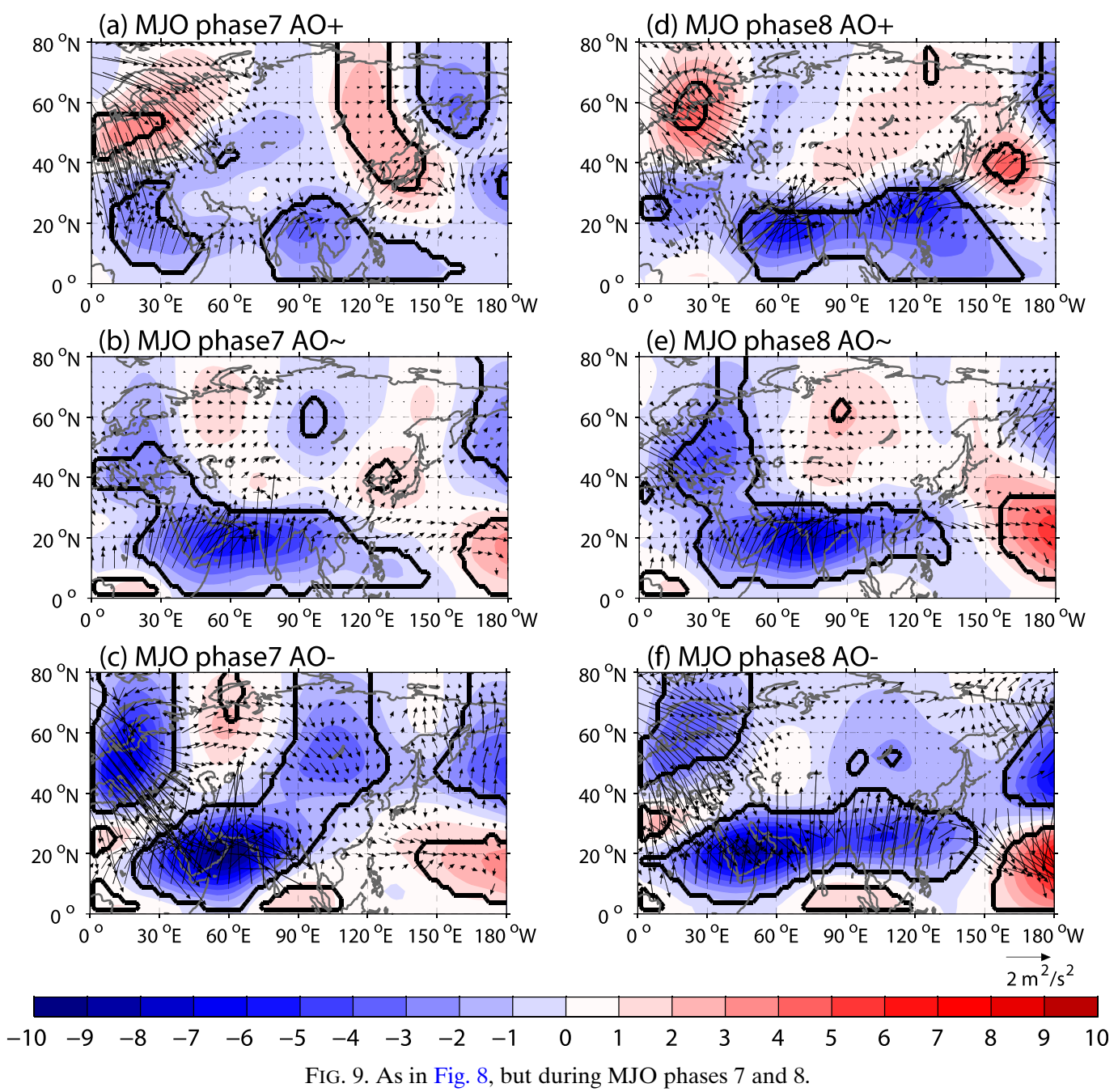

The difference in the mid- to high-latitude wave train between positive and negative AO may be related to the strength of the polar front jet. The Rossby wave train can propagate along both the polar front jet and the subtropical jet (Hoskins and Ambrizzi 1993; Lee and Kim 2003). The intensity of the jet may affect the wave energy propagation. A stronger jet may act as a more efficient waveguide and the downstream propagating Rossby wave train may have a larger amplitude (Matthews et al. 2004). Here, we compare the zonal winds in MJO phase 2 between positive and negative AO. The features in MJO phase 3 are similar. Strong subtropical jet is observed in both positive and negative AO (Figs. 10a,b). The polar front jet is located northward in positive $\mathrm{AO}$ than in negative AO. The difference of zonal winds between positive $\mathrm{AO}$ and negative $\mathrm{AO}$ displays two bands of negative values: one over South Asia and the other extending eastward from the Mediterranean Sea along $40^{\circ}-50^{\circ} \mathrm{N}$ (Fig. 10c). The two bands merge over East Asia.

The above features indicate a weakening of the polar front jet around $40^{\circ} \mathrm{N}$ (Lorenz and Hartmann 2003). The weakened polar front jet corresponds to the weakening of the Rossby wave train in positive AO (Fig. 8a).

\section{Summary and discussion}

Previous studies have shown the impacts of the MJO on winter surface temperature variations over East Asia, with colder and warmer temperatures over eastern China and northeastern East Asia in MJO phases 2-3 and 7-8, respectively (Jeong et al. 2005; Seo et al. 2016). Present studies compared surface air temperature anomalies in the eight MJO phases among positive, neutral, and negative AO phases during 1979-2016. The results indicated that the boreal winter temperature anomalies over East Asia are linked to the combined effects of the MJO and the AO. The cold anomalies over eastern China in MJO phases 2 and 3 are mainly 
(a) MJO phase2 $\mathrm{AO}+$

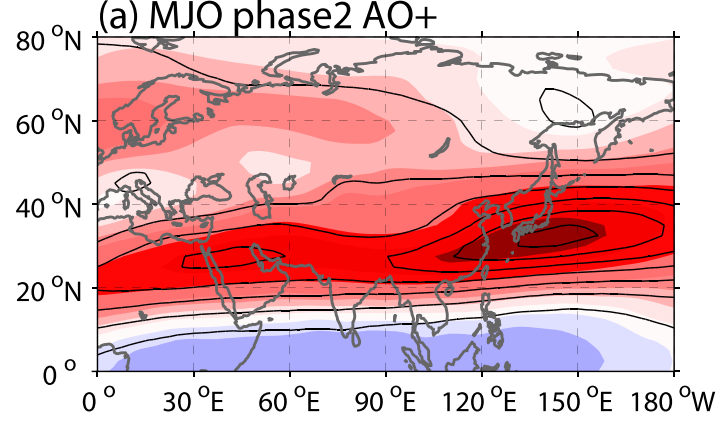

(b) MJO phase2 AO-
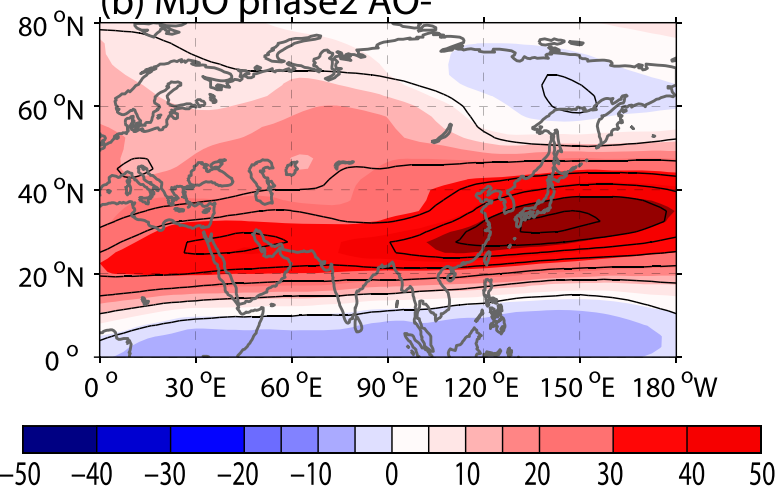

(c) MJO phase2 $\mathrm{AO}+$ minus $\mathrm{AO}-$

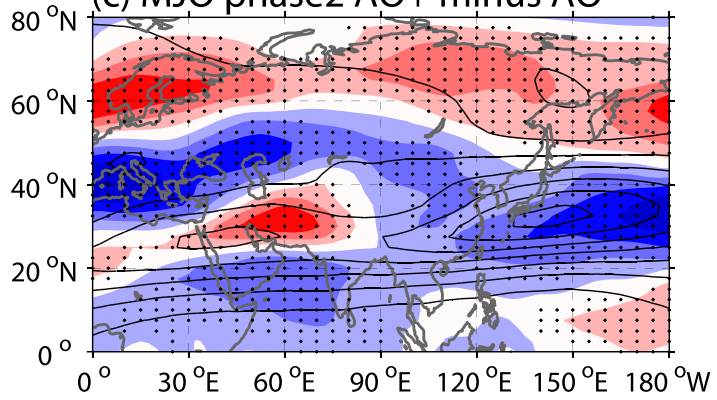

\begin{tabular}{llllllllllll|l|l|}
\hline & -15 & -12 & -9 & -6 & -3 & 0 & 3 & 6 & 9 & 12 & 15
\end{tabular}

FIG. 10. Composite zonal wind at $300 \mathrm{hPa}$ (shading; $\mathrm{m} \mathrm{s}^{-1}$ ) in MJO phase 2 during (a) positive and (b) negative AO. (c) The difference of zonal winds between positive and negative AO. Contours are climatological winter zonal winds. Contour interval is $10 \mathrm{~m} \mathrm{~s}^{-1}$. Black dots denote zonal wind difference significant at the $95 \%$ confidence level.

associated with positive AO. The warm anomalies over eastern China in MJO phase 7 are mainly associated with neutral $\mathrm{AO}$, and in $\mathrm{MJO}$ phase 8 warm anomalies appear in positive and neutral AO. Regional mean temperature anomalies over northeastern East Asia are negative when $\mathrm{AO}$ is negative but positive during positive $\mathrm{AO}$ in six of the eight MJO phases.

The AO can exert influences on temperature anomalies over East Asia in two ways. One is the Rossby wave train over the mid- to high-latitude Eurasian continent.
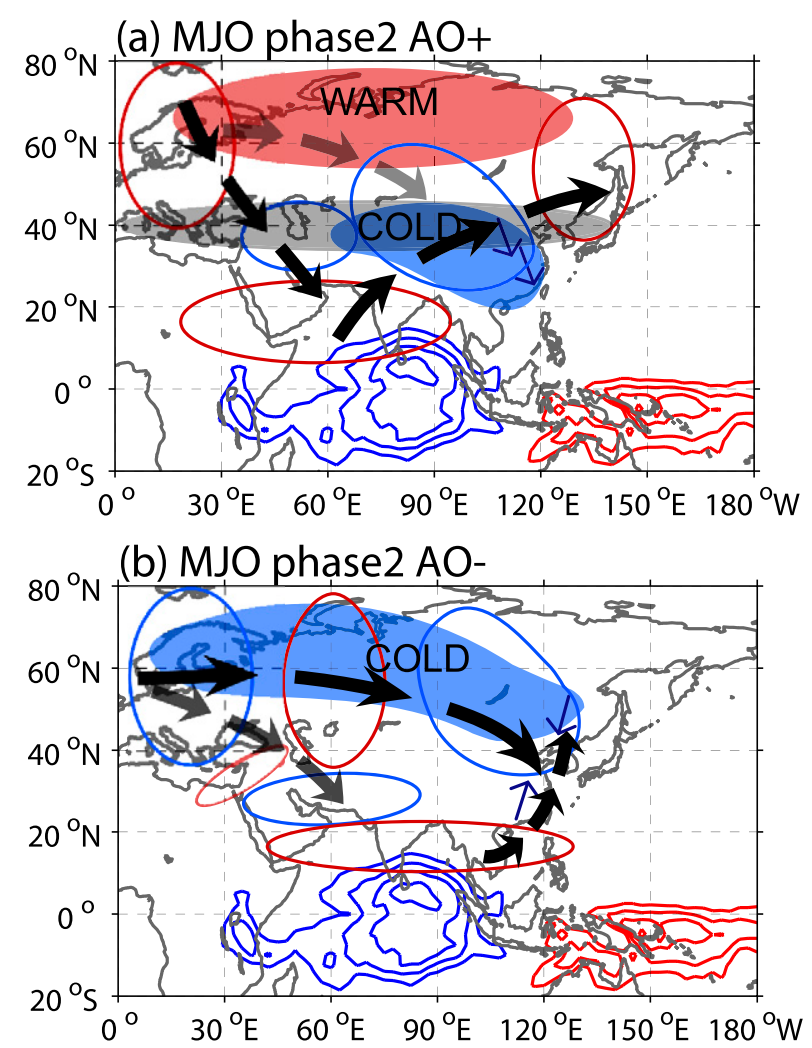

FIG. 11. Schematic diagrams showing the main features of surface temperature anomalies in MJO phase 2 during (a) positive and (b) negative AO. The red and blue contours over the tropical region denote positive and negative OLR anomalies, respectively. The red and blue shadings over the Eurasian continent represent warm and cold surface temperature anomalies, respectively. The thin blue arrows over East Asia indicate anomalous surface wind direction. The red and blue contours over the Eurasian continent denote positive and negative streamfunction anomalies, respectively, at $300 \mathrm{hPa}$. The bold black and gray arrows indicate strong and weak Rossby wave train fluxes at $300 \mathrm{hPa}$, respectively. The gray shading along $40^{\circ} \mathrm{N}$ in (a) denotes the divergence of the eddy momentum flux in positive $\mathrm{AO}$.

The other is the southeastward dispersion of Rossby wave energy that modulates the intensity and location of an MJO-triggered anomalous anticyclone or cyclone over the Arabian Sea. In MJO phases 2 and 3, the midto high-latitude wave train is stronger in negative $\mathrm{AO}$ than in positive AO (Fig. 11). The MJO-related wave source over the Arabian Sea is enhanced by the southeastward dispersion of wave energy in positive $\mathrm{AO}$, leading to the northeastward propagation of the wave train from South to East Asia and the formation of an anomalous cyclone over the midlatitude Asia (Fig. 11a). Consequently, the cold anomalies invade eastern China. The negative AO weakens the wave source over South Asia on its western part and pushes it eastward, leading to the eastward shift of the poleward wave train 
(Fig. 11b). As such, the anomalous cyclone over Asia is mainly related to the mid- to high-latitude wave train and is located at higher latitudes. Accordingly, cold anomalies mainly affect northeastern East Asia. In MJO phases 7-8, the South Asian wave source is enhanced in negative AO, but is weakened and shifts eastward in positive AO. The mid- to high-latitude wave train appears in both positive and negative AO. In negative AO, the coexistence of negative height anomalies over the subtropics and mid- to high-latitude Asia leads to a weakened meridional gradient of height anomalies. As such, the subtropical wave train cannot affect midlatitude Asia. In positive AO, the poleward wave train propagates from Southeast Asia to northeastern Asia. The difference in the mid- to high-latitude wave train between positive and negative $\mathrm{AO}$ in $\mathrm{MJO}$ phases $2-3$ is associated with the change in the intensity and location of the polar front jet. The mid- to high-latitude westerly winds are larger in negative $\mathrm{AO}$ than in positive $\mathrm{AO}$, leading to a larger amplitude of wave train when $\mathrm{AO}$ is negative.

This study focused on the combined effect of the $\mathrm{MJO}$ and the $\mathrm{AO}$ on the temperature anomalies over East Asia. Previous studies have suggested an interaction between the AO and the MJO (Miller et al. 2003; Zhou and Miller 2005; L'Heureux and Higgins 2008; Lin et al. 2009). Zhou and Miller (2005) indicated that the MJO can interact with the AO through tropospheric meridional Rossby wave propagation over the North Pacific. L'Heureux and Higgins (2008) suggested the similarity of surface temperature anomalies related to the $\mathrm{MJO}$ and the $\mathrm{AO}$, and the surface pattern of the AO can be changed in certain phases of the MJO. The MJO may also be linked to the AO through the propagation of stratospheric planetary waves, which may be manifested as the connection between the MJO and the variation of the polar vortex and the occurrence of the stratospheric sudden warmings (Garfinkel et al. 2012; Garfinkel and Schwartz 2017). This indicates a complex cause and effect relationship between MJO- and AO-related circulation changes in the troposphere and stratosphere on different time scales. This interaction may include both linear and nonlinear changes, which, however, is beyond the scope of the present study.

Acknowledgments. We appreciate comments from three anonymous reviewers that have helped the improvement of this manuscript. This study is supported by the National Natural Science Foundation of China (Grants 41705063, 41530425, 41775080, 41721004, and 41475081). The NCEP reanalysis 2 data were obtained from ftp://ftp.cdc.noaa.gov/.

\section{REFERENCES}

Abdillah, M. R., Y. Kanno, and T. Iwasaki, 2018: Tropicalextratropical interactions associated with East Asian cold air outbreaks. Part II: Intraseasonal variation. J. Climate, 31, 473490, https://doi.org/10.1175/JCLI-D-17-0147.1.

Baxter, S., S. Weaver, J. Gottschalck, and Y. Xue, 2014: Pentad evolution of wintertime impacts of the Madden-Julian oscillation over the contiguous United States. J. Climate, 27, 73567367, https://doi.org/10.1175/JCLI-D-14-00105.1.

Bueh, C., N. Shi, and Z. Xie, 2011: Large-scale circulation anomalies associated with persistent low temperature over southern China in January 2008. Atmos. Sci. Lett., 12, 273-280, https:// doi.org/10.1002/asl.333.

Ding, Y., 1990: Build-up, air mass transformation and propagation of Siberian high and its relations to cold surge in East Asia. Meteor. Atmos. Phys., 44, 281-292, https://doi.org/10.1007/ BF01026822.

— , and T. N. Krishnamurti, 1987: Heat budget of the Siberian high and the winter monsoon. Mon. Wea. Rev., 115, 2428-2449, https://doi.org/10.1175/1520-0493(1987)115<2428: $\mathrm{HBOTSH}>2.0 . \mathrm{CO} ; 2$.

Ferranti, L., T. N. Palmer, F. Molteni, and E. Klinker, 1990: Tropical-extratropical interaction associated with the 3060 day oscillation and its impact on medium and extended range prediction. J. Atmos. Sci., 47, 2177-2199, https://doi.org/ 10.1175/1520-0469(1990)047<2177:TEIAWT>2.0.CO;2.

Garfinkel, C. I., and C. Schwartz, 2017: MJO-related tropical convection anomalies lead to more accurate stratospheric vortex variability in subseasonal forecast models. Geophys. Res. Lett., 44, 10 054-10 062, https://doi.org/10.1002/ 2017 GL074470.

—, S. B. Feldstein, D. W. Waugh, C. Yoo, and S. Lee, 2012: Observed connection between stratospheric sudden warmings and the Madden-Julian oscillation. Geophys. Res. Lett., 39, L18807, https://doi.org/10.1029/2012GL053144.

Gong, D.-Y., S.-W. Wang, and J.-H. Zhu, 2001: East Asian winter monsoon and Arctic Oscillation. Geophys. Res. Lett., 28, 2073-2076, https://doi.org/10.1029/2000GL012311.

He, J., H. Lin, and Z. Wu, 2011: Another look at influences of the Madden-Julian Oscillation on the wintertime East Asian weather. J. Geophys. Res., 116, A05315, https://doi.org/10.1029/ 2010JA016252.

He, S., Y. Gao, F. Li, H. Wang, and Y. He, 2017: Impact of Arctic Oscillation on the East Asian climate: A review. Earth Sci. Rev., 164, 48-62, https://doi.org/10.1016/j.earscirev.2016.10.014.

_, H. Wang, Y. Gao, and F. Li, 2018: Recent intensified impact of December Arctic Oscillation on subsequent January temperature in Eurasia and North Africa. Climate Dyn., https://doi.org/10.1007/s00382-018-4182-7.

Hoskins, B. J., and T. Ambrizzi, 1993: Rossby wave propagation on a realistic longitudinally varying flow. J. Atmos. Sci., 50, 1661-1671, https://doi.org/10.1175/1520-0469(1993)050<1661: RWPOAR $>2.0 . \mathrm{CO} ; 2$.

Jeong, J.-H., and C.-H. Ho, 2005: Changes in occurrence of cold surges over East Asia in association with Arctic Oscillation. Geophys. Res. Lett., 32, L14704, https://doi.org/10.1029/2005GL023024.

, B.-M. Kim, and W.-T. Kwon, 2005: Influence of the Madden-Julian oscillation on wintertime surface air temperature and cold surges in East Asia. J. Geophys. Res., 110, D11104, https://doi.org/10.1029/2004JD005408.

Jin, F., and B. J. Hoskins, 1995: The direct response to tropical heating in a baroclinic atmosphere. J. Atmos. Sci., 52, 
307-319, https://doi.org/10.1175/1520-0469(1995)052<0307: TDRTTH $>2.0 . \mathrm{CO} ; 2$.

Kanamitsu, M., W. Ebisuzaki, J. Woollen, S.-K. Yang, J. J. Hnilo, M. Fiorino, and G. L. Potter, 2002: NCEP-DOE AMIP-II Reanalysis (R-2). Bull. Amer. Meteor. Soc., 83, 1631-1643, https://doi.org/10.1175/BAMS-83-11-1631.

Kim, B.-M., G.-H. Lim, and K.-Y. Kim, 2006: A new look at the midlatitude-MJO teleconnection in the Northern Hemisphere winter. Quart. J. Roy. Meteor. Soc., 132, 485-503, https://doi.org/10.1256/qj.04.87.

Kunkel, K. E., R. A. Pielke, and S. A. Changnon, 1999: Temporal fluctuations in weather and climate extremes that cause economic and human health impacts: A review. Bull. Amer. Meteor. Soc., 80, 1077-1098, https://doi.org/10.1175/1520-0477(1999)080<1077: TFIWAC $>2.0 . \mathrm{CO} ; 2$.

Lee, S., and H.-K. Kim, 2003: The dynamical relationship between subtropical and eddy-driven jets. J. Atmos. Sci., 60, 1490-1503, https://doi.org/10.1175/1520-0469(2003)060<1490: TDRBSA $>2.0 . \mathrm{CO} ; 2$.

L'Heureux, M. L., and R. W. Higgins, 2008: Boreal winter links between the Madden-Julian Oscillation and the Arctic Oscillation. J. Climate, 21, 3040-3050, https://doi.org/10.1175/ 2007JCLI1955.1.

Li, X., G. Gollan, R. J. Greatbatch, and R. Lu, 2018: Intraseasonal variation of the East Asian summer monsoon associated with the Madden-Julian oscillation. Atmos. Sci. Lett., 19, e794, https://doi.org/10.1002/asl.794.

Lin, H., G. Brunet, and J. Derome, 2009: An observed connection between the North Atlantic Oscillation and the MaddenJulian oscillation. J. Climate, 22, 364-380, https://doi.org/ 10.1175/2008JCLI2515.1.

Lorenz, D. J., and D. L. Hartmann, 2003: Eddy-zonal flow feedback in the Northern Hemisphere winter. J. Climate, 16, 1212-1227, https://doi.org/10.1175/1520-0442(2003)16<1212: EFFITN $>2.0 . C O ; 2$.

Madden, R. A., and P. R. Julian, 1971: Detection of a 40-50 day oscillation in the zonal wind in the tropical Pacific. J. Atmos. Sci., 28, 702-708, https://doi.org/10.1175/1520-0469(1971)028<0702: DOADOI $>2.0 . \mathrm{CO} ; 2$.

— , and — 1972: Description of global-scale circulation cells in the tropics with a 40-50 day period. J. Atmos. Sci., 29, 1109-1123, https://doi.org/10.1175/1520-0469(1972)029<1109: DOGSCC $>2.0 . \mathrm{CO} ; 2$.

Matthews, A. J., B. J. Hoskins, and M. Masutani, 2004: The global response to tropical heating in the Madden-Julian oscillation during the northern winter. Quart. J. Roy. Meteor. Soc., 130, 1991-2011, https://doi.org/10.1256/qj.02.123.

Miller, A. J., S. Zhou, and S.-K. Yang, 2003: Relationship of the Arctic and Antarctic Oscillations to the outgoing longwave radiation. J. Climate, 16, 1583-1592, https://doi.org/10.1175/ 1520-0442-16.10.1583.

Park, H.-J., and J.-B. Ahn, 2016: Combined effect of the Arctic Oscillation and the western Pacific pattern on East Asia winter temperature. Climate Dyn., 46, 3205-3221, https://doi.org/ 10.1007/s00382-015-2763-2.

Park, T.-W., C.-H. Ho, S. Yang, and J.-H. Jeong, 2010: Influences of Arctic Oscillation and Madden-Julian oscillation on cold surges and heavy snowfalls over Korea: A case study for the winter of 2009-2010. J. Geophys. Res., 115, D23122, https:// doi.org/10.1029/2010JD014794.

- ——, and — 2011: Relationship between the Arctic Oscillation and cold surges over East Asia. J. Climate, 24, 68-83, https://doi.org/10.1175/2010JCLI3529.1.
,-- - - and Y. Deng, 2014: A synoptic and dynamical characterization of wave-train and blocking cold surge over East Asia. Climate Dyn., 43, 753-770, https://doi.org/10.1007/ s00382-013-1817-6.

Plumb, R. A., 1985: On the three-dimensional propagation of stationary waves. J. Atmos. Sci., 42, 217-229, https://doi.org/ 10.1175/1520-0469(1985)042<0217:OTTDPO > 2.0.CO;2.

Sardeshmukh, P. D., and B. J. Hoskins, 1988: The generation of global rotational flow by steady idealized tropical divergence. J. Atmos. Sci., 45, 1228-1251, https://doi.org/10.1175/15200469(1988)045<1228:TGOGRF>2.0.CO;2.

Seo, K.-H., and S.-W. Son, 2012: The global atmospheric circulation response to tropical diabatic heating associated with the Madden-Julian oscillation during northern winter. J. Atmos. Sci., 69, 79-96, https://doi.org/10.1175/2011JAS3686.1.

—_, and H. Lee, 2017: Mechanisms for a PNA-like teleconnection pattern in response to the MJO. J. Atmos. Sci., 74, 1767-1781, https://doi.org/10.1175/JAS-D-16-0343.1.

- - H.-J. Lee, and D. M. W. Frierson, 2016: Unraveling the teleconnection mechanisms that induce wintertime temperature anomalies over the Northern Hemisphere continents in response to the MJO. J. Atmos. Sci., 73, 3557-3571, https:// doi.org/10.1175/JAS-D-16-0036.1.

Shoji, T., Y. Kanno, T. Iwasaki, and K. Takaya, 2014: An isentropic analysis of the temporal evolution of East Asian cold air outbreaks. J. Climate, 27, 9337-9348, https://doi.org/10.1175/ JCLI-D-14-00307.1.

Song, L., and R. Wu, 2017: Processes for occurrence of strong cold events over eastern China. J. Climate, 30, 9247-9266, https:// doi.org/10.1175/JCLI-D-16-0857.1.

— , and — , 2018: Comparison of intraseasonal East Asian winter cold temperature anomalies in positive and negative phases of the Arctic Oscillation. J. Geophys. Res., 123, 85188537, https://doi.org/10.1029/2018JD028343.

— L L. Wang, W. Chen, and Y. Zhang, 2016: Intraseasonal variation of the strength of the East Asian trough and its climatic impacts in boreal winter. J. Climate, 29, 2557-2577, https:// doi.org/10.1175/JCLI-D-14-00834.1.

Takaya, K., and H. Nakamura, 2001: A formulation of a phaseindependent wave-activity flux for stationary and migratory quasigeostrophic eddies on a zonally varying basic flow. J. Atmos. Sci., 58, 608-627, https://doi.org/10.1175/ 1520-0469(2001)058<0608:AFOAPI >2.0.CO;2.

$\longrightarrow$, and $\longrightarrow$ 2005a: Geographical dependence of upper-level blocking formation associated with intraseasonal amplification of the Siberian high. J. Atmos. Sci., 62, 4441-4449, https:// doi.org/10.1175/JAS3628.1.

— of the cold Siberian high. J. Atmos. Sci., 62, 4423-4440, https:// doi.org/10.1175/JAS3629.1.

Thompson, D. W. J., and J. M. Wallace, 1998: The Arctic oscillation signature in the wintertime geopotential height and temperature fields. Geophys. Res. Lett., 25, 1297-1300, https://doi.org/ 10.1029/98GL00950.

— lation. Part I: Month-to-month variability. J. Climate, 13, 1000-1016, https://doi.org/10.1175/1520-0442(2000)013<1000: AMITEC $>2.0 . \mathrm{CO} ; 2$.

Watanabe, M., 2004: Asian jet waveguide and a downstream extension of the North Atlantic Oscillation. J. Climate, 17, 46744691, https://doi.org/10.1175/JCLI-3228.1.

Wen, M., S. Yang, A. Kumar, and P. Zhang, 2009: An analysis of the large-scale climate anomalies associated with the snowstorms 
affecting China in January 2008. Mon. Wea. Rev., 137, 11111131, https://doi.org/10.1175/2008MWR2638.1.

Wheeler, M. C., and H. H. Hendon, 2004: An all-season realtime multivariate MJO index: Development of an index for monitoring and prediction. Mon. Wea. Rev., 132, 1917 1932, https://doi.org/10.1175/1520-0493(2004)132<1917: AARMMI $>2.0 . \mathrm{CO} ; 2$.

Wu, B., and J. Wang, 2002: Winter Arctic Oscillation, Siberian high and East Asian winter monsoon. Geophys. Res. Lett., 29, 1897, https://doi.org/10.1029/2002GL015373.

Yoo, C., S. Lee, and S. B. Feldstein, 2012: Mechanisms of Arctic surface air temperature change in response to the Madden-Julian oscillation. J. Climate, 25, 5777-5790, https://doi.org/10.1175/ JCLI-D-11-00566.1.
Zhang, C., 2005: Madden-Julian Oscillation. Rev. Geophys., 43, RG2003, https://doi.org/10.1029/2004RG000158.

Zhang, Y., K. R. Sperber, and J. S. Boyle, 1997: Climatology and interannual variation of the East Asian winter monsoon: Results from the 1979-95 NCEP/NCAR reanalysis. Mon. Wea. Rev., 125, 2605-2619, https://doi.org/10.1175/1520-0493(1997)125<2605: CAIVOT $>2.0 . \mathrm{CO} ; 2$.

Zhou, S., and A. J. Miller, 2005: The interaction of the MaddenJulian oscillation and the Arctic Oscillation. J. Climate, 18, 143-159, https://doi.org/10.1175/JCLI3251.1.

Zhou, W., J. C. L. Chan, W. Chen, J. Ling, J. G. Pinto, and Y. Shao, 2009: Synoptic-scale controls of persistent low temperature and icy weather over southern China in January 2008. Mon. Wea. Rev., 137, 3978-3991, https://doi.org/10.1175/2009MWR2952.1. 